\title{
Association of exogenous phospholipids with spermatozoa
}

\author{
R. W. Evans* and B. P. Setchell \\ A.R.C. Institute of Animal Physiology, Babraham, Cambridge CB2 4AT, U.K.
}

\begin{abstract}
Summary. Boar, bull and ram spermatozoa were studied after incubation in a medium containing phospholipids. Autoradiography and birefringent examination of spermatozoa after incubation with labelled phosphatidylcholine indicated that liposomes of this phospholipid associated with spermatozoa. The association was almost instantaneous. The large multilayer liposomes formed during the experimental procedure resulted in a few of the spermatozoa acquiring most of the phosphatidylcholine. Little phosphatidylcholine was observed unassociated with spermatozoa although measurements of the partition between spermatozoa and medium showed that only boar spermatozoa associated with almost all the phospholipid. No evidence was obtained that phosphatidylethanolamine or phosphatidylinositol associated with the spermatozoa.
\end{abstract}

\section{Introduction}

Since Phillips \& Lardy (1940) first recommended the addition of egg yolk to semen, the use of egg yolk as a protective agent against cold shock has become widely practised. Lipoproteins and phosphatidylcholine have been implicated as the active factors within the egg yolk although only the lipoproteins are beneficial during storage (Kampschmidt, Meyer \& Herman, 1953; Blackshaw, 1954; Blackshaw \& Salisbury, 1957; Foulkes, 1977; Foulkes \& Stewart, 1977). The mode of action of the lipoproteins and the phosphatidylcholine is unclear. It is unlikely that the phosphatidylcholine serves as a source of oxidizable substrate because Bomstein \& Steberl (1957), Dawson, Mann \& White (1957) and Scott \& Dawson (1968) have demonstrated that it is not appreciably hydrolysed by either ram or bull spermatozoa. Beljkevic, Kljucareva, Rombe \& Filaretova (1959), cited by Quinn \& White (1966), postulated that phosphatidylcholine bound $\mathrm{Ca}^{2+}$ ions which were released from spermatozoa during cold shock and hence prevented a damaging increase in concentration of this ion. Watson (1975) suggested that the reversible attachment of egg yolk to the sperm plasma membrane somehow protects the spermatozoa, and the protective binding of the lipoprotein fraction has been confirmed (Foulkes, 1977).

A report by Butler \& Roberts (1975) indicated that the presence of phosphatidylcholine during cooling had no effect on boar spermatozoa. Similarly, phosphatidylethanolamine had no effect but phosphatidylserine exhibited some protective action (assessed from the percentage of motile spermatozoa and of spermatozoa with normal acrosomes).

In the present investigation, we have undertaken autoradiography and birefringent examination of spermatozoa after incubation with radioactively labelled phospholipids in an attempt to obtain morphological evidence of any association between the spermatozoa and the phospholipids.

\section{Materials and Methods}

Continuous collections of ram and boar testicular semen were made by the technique of Voglmayr, Scott, Setchell \& Waites (1967) as modified by Suominen \& Setchell (1972), except that the boars were kept in a small pen after surgery and not restrained in a sling. To obtain epididymal contents the

* Present address: Department of Nutritional Sciences, University of California, Berkeley, California 94720 , U.S.A. 
testes, epididymides and ductus deferentes of rams and boars were removed immediately after death. An incision was made into the ductus deferens and polyvinylchloride tubing $(0.8 \mathrm{~mm}$ i.d., $1.2 \mathrm{~mm}$ o.d.) was inserted towards the cauda epididymidis. Two ligatures were tied around the tubing and the ductus deferens. Pressure was applied to the cauda epididymidis and the epididymal contents were collected. When flow ceased it could sometimes be restarted by injecting Krebs-Ringerbicarbonate (KRB) buffer containing (mM): $\mathrm{Na}^{+}, 144 ; \mathrm{K}^{+}, 6 \cdot 0 ; \mathrm{Ca}^{2+}, 2 \cdot 5 ; \mathrm{Mg}^{2+}, 1 \cdot 2 ; \mathrm{Cl}^{-}, 129$; $\mathrm{HCO}_{3}^{-}, 25 ; \mathrm{H}_{2} \mathrm{PO}_{4}^{-}, 1 \cdot 2\left(\mathrm{pH} 7 \cdot 1,32^{\circ} \mathrm{C}\right)$ into the cauda epididymidis. Boar semen was obtained by manual collection with a dummy sow. The semen was strained through cheesecloth to remove gel. Bull and ram semen were obtained by collection into an artificial vagina. To separate spermatozoa and fluid, all epididymal samples, and ram and bull semen were diluted 5-fold with KRB buffer (pH 7.1, 32 ${ }^{\circ} \mathrm{C}$ ) before centrifugation at $800 \mathrm{~g}$ for $10 \mathrm{~min}$ at $32^{\circ} \mathrm{C}$. All testicular semen and ejaculated boar semen samples were centrifuged at $800 \mathrm{~g}$ for $10 \mathrm{~min}$ at $32^{\circ} \mathrm{C}$. The supernatants were immediately removed and the spermatozoa were resuspended to the original volume in KRB buffer.

Phospholipid in chloroform-methanol $(2: 1, \mathrm{v} / \mathrm{v})$ was placed in an incubation tube and dried under nitrogen. ${ }^{32} \mathrm{P}$-labelled phospholipids were extracted and purified from baker's yeast which had been grown in the presence of $\left[{ }^{32} \mathrm{P}\right]$ orthophosphate (Hazelwood \& Dawson, 1975) and about $10 \mu \mathrm{g}$ phosphatidylcholine, $30 \mu \mathrm{g}$ phosphatidylethanolamine or $20 \mu \mathrm{g}$ phosphatidylinositol per $10^{8}$ spermatozoa was used. Fatty acid analysis revealed that the $\left.{ }^{32} \mathrm{P}\right]$ phosphatidylcholine contained $77 \%$ palmitic $(16: 0)$ and $14 \%$ stearic $(18: 0)$ acid whereas the [ $\left.{ }^{32} \mathrm{P}\right]$ phosphatidylethanolamine contained $63 \%$ palmitic and $32 \%$ stearic acid. $\left[{ }^{3} \mathrm{H}\right] \mathrm{Ph}$ osphatidylcholine and $\left[{ }^{3} \mathrm{H}\right]$ phosphatidylethanolamine were similarly purified from yeast which had been grown in the presence of [methyl- $\left.{ }^{3} \mathrm{H}\right]-$ choline chloride or $\left[2-{ }^{3} \mathrm{H}\right]$ ethanolamine with excess phosphate respectively. Spermatozoa in the appropriate medium (either seminal plasma or KRB buffer) plus an acid-washed glass bead ( $1 \mathrm{~mm}$ diam.) were added and the tube placed on a rotamixer for $\mathbf{4 0}$ seconds. The tubes were then incubated at $32^{\circ} \mathrm{C}$ for $30 \mathrm{~min}$. After incubation, $5 \mathrm{ml} \mathrm{KRB}$ buffer were added to the incubation tube and the contents transferred to a centrifuge tube $(1 \mathrm{~cm}$ diam.) for sedimentation of the spermatozoa at $32^{\circ} \mathrm{C}, 800 \mathrm{~g}$, for $5 \mathrm{~min}$. The supernatant was removed and the washing procedure repeated. After again resuspending in $5 \mathrm{ml} \mathrm{KRB}$ buffer, samples were removed for autoradiography and observations of birefringence. Electron microscope studies (F. B. P. Wooding, unpublished observations) have shown that this treatment does not damage the spermatozoa.

For autoradiography, the sample was diluted to about $5 \times 10^{6}$ spermatozoa $/ \mathrm{ml}$ with $8.5 \%$ sucrose ( $w / v)$ or KRB buffer. A drop of this suspension was smeared onto a glass slide and allowed to dry. The slide was rinsed gently with distilled water, again allowed to dry, and then dipped into emulsion diluted 1:1 with water (Ilford: $\mathrm{K} 2$ for ${ }^{3} \mathrm{H}$; G5 for ${ }^{32} \mathrm{P}$ ) in a dark room and stored for the required time (up to 30 days for ${ }^{32} \mathrm{P}$; up to 136 days for ${ }^{3} \mathrm{H}$ ) in a plastic light-proof box at $3^{\circ} \mathrm{C}$. After exposure, the slide was developed in phen-X (diluted 1:3 with distilled water for ${ }^{32} \mathrm{P}$; diluted $1: 1$ with distilled water for $\left.{ }^{3} \mathrm{H}\right)$ for $10 \mathrm{~min}$ at $15^{\circ} \mathrm{C}$. The slide was then placed in a stop bath $(20 \mathrm{~g}$ chrome alum, $20 \mathrm{~g}$ sodium metabisulphite/litre distilled water) for $2 \mathrm{~min}$, fixed for $10 \mathrm{~min}$ in two parts of $30 \%$ sodium thiosulphate to one part stop bath (freshly made), placed for 10 min in distilled water and washed thoroughly in running tap water (Rogers, 1967). The slide was then stained for 5 min in $1 \%$ aqueous neutral red at room temperature, dehydrated in 50,70 and $90 \%$ methylated spirit in water and in absolute ethanol, cleared in xylol, and finally mounted with Xam (Neutral Xam; G. T. Gurr).

For observations on birefringence, a drop of the sperm suspension (about $5 \times 10^{6}$ spermatozoa $/ \mathrm{ml}$ KRB buffer) was smeared onto a glass slide and viewed through a microscope fitted with crossed polaroids.

To measure the partition of the $\left[{ }^{32} \mathrm{P}\right]$ phospholipid between the spermatozoa and medium, these were extracted with chloroform-methanol. Spermatozoa were homogenized in chloroform-methanol $(2: 1, \mathrm{v} / \mathrm{v})$ and left to stand for $30 \mathrm{~min}$ at room temperature. The extracts were washed with 0.2 volumes of water and thrice more with theoretical upper phase (chloroform-methanol-water, $3: 48: 47$, by vol.) as defined by Folch, Lees \& Sloane-Stanley (1957). Fluids were extracted with 10 vols chloroform-methanol $(1: 1, \mathrm{v} / \mathrm{v})$. After standing for $30 \mathrm{~min}$ at room temperature the extracts were washed with $0 \cdot 2$ volumes water and thrice more with theoretical upper phase. The ${ }^{32} \mathrm{P}$ in the upper and 
lower phases was estimated from its Cerenkov radiation (Plesums \& Bunch, 1971). The upper phase of the medium was counted to assess the production of water-soluble breakdown products, but these are not considered further.

\section{Results}

When washed ejaculated bull spermatozoa were incubated with ${ }^{32} \mathrm{P}$-labelled phosphatidylcholine, the background was high but there was clearly a concentration of grains in the area of the spermatozoa, particularly around the heads and following the tails (Pl. 1, Fig. 1). However, the proportion of spermatozoa associating with phosphatidylcholine under the conditions of these experiments was small, never exceeding 5\% (200 spermatozoa examined per slide). The autoradiographs obtained with ${ }^{32} \mathrm{P}$-labelled phosphatidylethanolamine after similar treatment (Pl. 1, Fig. 2) again exhibited a high background but there was no concentration of silver grains in the area of the spermatozoa. Similarly, there was no suggestion that the phosphatidylethanolamine or phosphatidylcholine associated with unwashed bull spermatozoa.

The results obtained after autoradiography of washed ejaculated ram spermatozoa previously incubated with phosphatidyl[Me- $\left.{ }^{3} \mathrm{H}\right]$ choline (PI. 1, Fig. 3) showed large clusters of grains around the spermatozoa. Some clusters were not on the spermatozoa. The background in the absence of labelled phospholipid consisted of occasional individual grains not clusters and, therefore, we believe that these clusters arose either from lipid which had not associated with spermatozoa or from lipid which had associated with spermatozoa during the incubation but had been dislodged during handling of the slides. Mechanical stress encountered during dipping the slides into emulsion could possibly remove lipid, from the sperm surface particularly, as the spermatozoa would now be dead. The surface characteristics of dead spermatozoa are known to be different from those of live spermatozoa (Bangham \& Hancock, 1955). It was noticed that the end of the slide, towards which excess emulsion was allowed to drain, contained a greater density of 'free' grains than the remainder of the slides. In an attempt to establish the effect of dipping into a solvent on the distribution of the grains, slides were dipped into distilled water before immersing them in emulsion. If the distilled water washing was omitted, 169 of the 200 clusters examined were apparently associated with spermatozoa and 31 were 'free'. After washing the figures became 192 and 8 respectively. Although both these figures indicate that most of the lipid was associated with spermatozoa this involved the labelling of only a few of the spermatozoa, again no more than $5 \%$ of the 200 spermatozoa examined per slide. After incubation with $\left[{ }^{3} \mathrm{H}\right]$ phosphatidylethanolamine very few clusters were evident on washed ejaculated ram spermatozoa and these contained only a few grains, making their distinction from background difficult.

Similar results were obtained with unwashed ejaculated ram spermatozoa, although the total number of spermatozoa associating with phosphatidylcholine did not exceed $3 \%$ of the 200 spermatozoa examined per slide.

Chemography caused problems during autoradiography of ${ }^{3} \mathrm{H}$-labelled samples. An autoradiograph of ram testicular spermatozoa after incubation with $\left[{ }^{3} \mathrm{H}\right]$ phosphatidylcholine is shown in Pl. 1, Figs 4 and 5. There appeared to be labelling in the post-acrosomal region but this 'labelling' did not increase with time of exposure and was regional on the slide, suggesting chemography rather than autoradiography. Also the grains were brownish rather than black and tended to be variable in size. Subsequently, similar results were obtained in the absence of lipid after dilution of the spermatozoa with KRB buffer. In the absence of phosphatidylcholine no such chemography was seen if the spermatozoa were diluted before autoradiography with $8.5 \%$ sucrose, but the presence of phosphatidylcholine (labelled or unlabelled) produced chemography. The substitution of phosphatidylethanolamine for the phosphatidylcholine eliminated the chemography. Slides (20) of spermatozoa previously incubated with labelled or unlabelled phosphatidylcholine and diluted with $8.5 \%$ sucrose or KRB buffer were coated with a layer $(5-10 \mathrm{~nm})$ of carbon before immersing in emulsion. No evidence of chemography on the post-acrosomal region was obtained with any of these slides but clusters of grains could be seen on the slides of spermatozoa incubated with labelled phosphatidylcholine. 
After incubation of ejaculated boar spermatozoa with phosphatidylcholine many liposomes were observed by birefringence around a few spermatozoa and there were almost no 'free' liposomes. When ejaculated bull spermatozoa or bull semen were incubated with phosphatidylcholine, liposomes of phosphatidylcholine were observed around the washed ejaculated spermatozoa but not around the unwashed cells; most of the liposomes were around the heads of the spermatozoa although some were on the tails. Very little 'free' phosphatidylcholine was observed. There appeared to be no tendency for phosphatidylethanolamine or phosphatidylinositol to associate with washed or unwashed ejaculated bull spermatozoa.

Table 1. The percentage of added [ ${ }^{32}$ P]phosphatidylcholine (mean \pm s.e.m., no. of samples in parentheses) which became associated with various types of spermatozoa

\begin{tabular}{lccr}
\hline \multicolumn{1}{c}{ Spermatozoa } & Ram & Boar & \multicolumn{1}{c}{ Bull } \\
\hline $\begin{array}{l}\text { Testicular } \\
\text { Epididymal }\end{array}$ & $23 \cdot 9 \pm 5 \cdot 3(19)$ & $\begin{array}{l}10 \cdot 7,13 \cdot 3(2) \\
18 \cdot 2,20 \cdot 4(2)\end{array}$ \\
$\begin{array}{l}\text { Ejaculated } \\
\text { Ejaculated, } \\
\text { washed }\end{array}$ & $26 \cdot 6 \pm 8 \cdot 2(4)$ & $96 \cdot 8 \pm 0 \cdot 4(11)$ & $2 \cdot 8 \pm 0 \cdot 9(12)$ \\
\hline
\end{tabular}

Incubation was for $30 \mathrm{~min}$ at $32^{\circ} \mathrm{C}$ in $\mathrm{KRB}$ buffer, $\mathrm{pH} 7 \cdot 1$. Mass of exogenous phospholipid added was about $0.01 \mathrm{mg} / 10^{8}$ spermatozoa. Control experiments with buffer but no spermatozoa gave a value of $9 \cdot 0 \pm 2 \cdot 2(25)$.

Measurements of the partition of labelled phosphatidylcholine between spermatozoa and medium (Table 1) showed that washed and unwashed ejaculated boar spermatozoa associated instantaneously (within $5 \mathrm{~min}$ ) with almost all the added phosphatidylcholine, whereas ejaculated bull and ram, testicular ram and boar and epididymal boar spermatozoa associated with comparatively little phosphatidylcholine. Washing of ejaculated ram and bull spermatozoa increased the amount of lipid associating with them.

\section{Discussion}

The ${ }^{32} \mathrm{P}$ and ${ }^{3} \mathrm{H}$ autoradiography results, as well as the birefringence observations, support the view that phosphatidylcholine associates with spermatozoa. Of the spermatozoa examined using these techniques (testicular ram, washed and unwashed ejaculated boar, ram and bull spermatozoa), only the unwashed ejaculated bull spermatozoa did not associate with exogenous phosphatidylcholine. The relevance of these results to the role of egg yolk and phosphatidylcholine during storage of spermatozoa is not immediately clear. The presence of egg yolk improves the survival rate of bull, ram and boar spermatozoa during storage at low temperatures (Phillips \& Lardy, 1940; Salisbury, Fuller \& Willett, 1941 ; Watson \& Martin, 1974; Pursel \& Johnson, 1975), and bull spermatozoa are the most capable of withstanding storage, although in the present experiments they did not appear to associate with phosphatidylcholine at $32^{\circ} \mathrm{C}$. Semen proteins may compete with the spermatozoa for the available phospholipid and the routine extensive dilution of bull spermatozoa, before storage, may allow the spermatozoa to associate with phosphatidylcholine as washed bull ejaculated spermatozoa were observed to do. It is also possible that low temperatures, below $32^{\circ} \mathrm{C}$, would promote association of phosphatidylcholine with ejaculated bull spermatozoa.

In contrast, the other lipids tested (phosphatidylethanolamine and phosphatidylinositol) did not appear to associate with spermatozoa. The different charges on the phospholipid molecules may account for the various responses. At a physiological $\mathrm{pH}$ phosphatidylcholine is a zwitterion (electrically neutral), phosphatidylethanolamine would have a small negative charge due to partial 

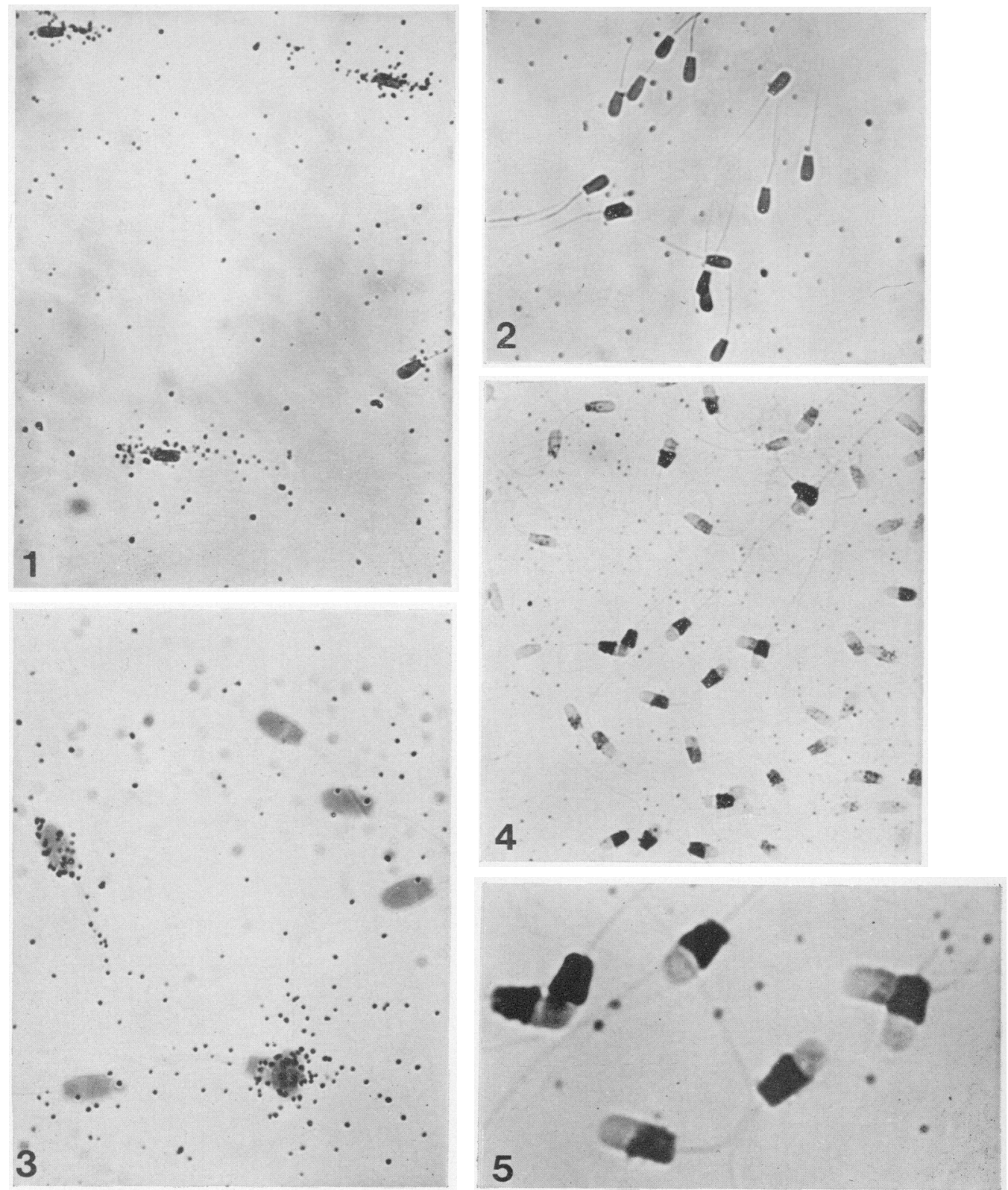

Fig. 1. Autoradiograph of washed ejaculated bull spermatozoa after incubation $\left(30 \mathrm{~min}, 32^{\circ} \mathrm{C}\right)$ in $\mathrm{KRB}$ buffer (pH 7·1) with ${ }^{32}$ P-labelled phosphatidylcholine. Sperm suspension diluted with KRB buffer. Exposure: 7 days.

Fig. 2. As Fig. 1 but with $\left[{ }^{32} \mathrm{P}\right]$ phosphatidylethanolamine.

Fig. 3. Autoradiograph of washed ejaculated ram spermatozoa after incubation $\left(30 \mathrm{~min}, 32^{\circ} \mathrm{C}\right)$ in $\mathrm{KRB}$ buffer (pH 7.1) with $\left[{ }^{3} \mathrm{H} \mid\right.$ phosphatidylcholine. Sperm suspension diluted with KRB buffer. Exposure: 100 days.

Figs 4 and 5. Autoradiographs of testicular ram spermatozoa showing chemography after incubation $\left(30 \mathrm{~min}, 32^{\circ} \mathrm{C}\right)$ in $\mathrm{KRB}$ buffer $(\mathrm{pH} 7 \cdot 1)$ with $\left[{ }^{3} \mathrm{H}\right]$ phosphatidylcholine. Sperm suspension diluted with $8 \cdot 5 \%$ sucrose. Exposure: 5 days. Fig. $4, \times 850$; Fig. $5, \times 2500$. 
deprotonization of the amino group, and phosphatidylinositol would be fully negatively charged (Dawson, 1966). Phosphatidylserine is an acidic phospholipid and may be expected to behave like phosphatidylinositol. Nevertheless, a protective action of phosphatidylserine during cooling of boar spermatozoa has been reported by Butler \& Roberts (1975). The procedures used by Butler \& Roberts (1975) were quite different from those used in the present investigation, and unfortunately we had no labelled phosphatidylserine available to study. In addition, Butler \& Roberts (1975) reported that different batches of phosphatidylserine varied in the effectiveness of their protective action, suggesting that comparison of different phospholipids would be difficult, particularly as the phospholipids were obtained from natural sources and contained a wide variety of fatty acids.

Under the conditions of our experiments, individual spermatozoa could associate with very large liposomes of phosphatidylcholine. Most of the spermatozoa remained free of exogenous lipids suggesting that any beneficial effect of phosphatidylcholine would be exerted on only a small percentage of the spermatozoa or that these spermatozoa were somehow different from the rest. Sonication of the lipid before addition of spermatozoa would considerably reduce the size of the liposomes and might increase the percentage of spermatozoa associating with lipid.

The post-acrosomal chemography appeared to be caused by a chemical reaction involving the sperm surface and either phosphatidylcholine or ionic components of the KRB buffer. It occurred whether the phosphatidylcholine was labelled or unlabelled and in the absence of phosphatidylcholine if the spermatozoa were diluted with KRB buffer and not $8.5 \%$ sucrose. Post-acrosomal chemography was absent if a layer of carbon was interposed between the emulsion and the spermatozoa. The significance of these observations is not clear but they do indicate that the surface properties of the post-acrosomal region are different from those on the remaining surface of the spermatozoon.

We thank Dr R. M. C. Dawson for providing labelled phospholipids, Mr L. Jarvis for producing the autoradiography slides, Mr N. Miller and Dr A. D. Bangham for help with the birefringence work, and the Meat and Livestock Commission for a scholarship (R.W.E.).

\section{References}

Bangham, A.D. \& Hancock, J.L. (1955) A new method for counting live and dead spermatozoa. Nature, Lond. 176, 656.

Blackshaw, A.W. (1954) The prevention of temperature shock of bull and ram semen. Aust. J. biol. Sci. 7, 573-582.

Blackshaw, A.W. \& Salisbury, G.W. (1957) Factors influencing metabolic activity of bull spermatozoa. II. Cold shock and its prevention. J. Dairy Sci. 40, 1099-1106.

Bomstein, R.A. \& Steberl, E.A. (1957) The utilisation of phospholipids by bovine spermatozoa. Expl Cell. Res. 12, 254-264.

Butler, J.W. \& Roberts, T.K. (1975) Effects of some phosphatidyl compounds on boar spermatozoa following cold shock or slow cooling. J. Reprod. Fert. 43, 183-187.

Dawson, R.M.C. (1966) The metabolism of animal phospholipids and their turnover in cell membranes. In Essays in Biochemistry, Vol. 2, pp. 69-116. Eds P. N. Campbell \& G. N. Greville. Academic Press, London.

Dawson, R.M.C., ManN, T. \& White, I.G. (1957) Glycerylphosphorylcholine and phosphorylcholine in semen and their relation to choline. Biochem. $J$. 65, 627-634.

Folch, J., Lees, M. \& Sloane-Stanley, G.H. (1957) A simple method for the isolation and purification of total lipids from animal tissues. J. biol. Chem. 226, 497-505.

Foulkes, J.A. (1977) The separation of lipoproteins from egg yolk and their effect on the motility and integrity of bovine spermatozoa. J. Reprod. Fert. 49, 277-284.

Foulkes, J.A. \& Stewart, D.L. (1977) Fertility of dairy cattle after artificial insemination with semen frozen in a lipoprotein diluent. $J$. Reprod. Fert. 51, 175-177.

Hazelwood, G.P. \& Dawson, R.M.C. (1975) Isolation and properties of a phospholipid-hydrolysing bacterium from ovine rumen fluid. J. gen. Microbiol. 89, $163-174$.

Kampschmidt, R.F., Meyer, D.T. \& Herman, H.A. (1953) Lipid and lipoprotein constituents of egg yolk in the resistance and storage of bull spermatozoa. J. Dairy Sci. 36, 733-742

Phillips, P.H. \& LARdy, H.A.A. (1940) Yolk buffer pabulum for the preservation of bull semen. $J$. Dairy Sci. 23, 399-404.

Plesums, J. \& Bunch, W.H. (1971) Measurement of phosphorus following ${ }^{32} \mathrm{P}$ Cerenkov counting. Analyt. Biochem. 42, 360-362.

Pursel, V.G. \& Johnson, L.A. (1975) Freezing of boar spermatozoa: fertilising capacity with concentrated semen and a new thawing procedure. J. Anim. Sci. 40, 99-102. 
QuinN, P.J. \& White, I.G. (1966) Effect of cold shock and deep freezing on the concentration of major cations in spermatozoa. J. Reprod. Fert. 12, 265-270.

Rogers, A.W. (1967) Liquid-emulsion techniques for grain-density autoradiographs. In Techniques of Autoradiography, pp. 253-272. Elsevier, Amsterdam.

SAlisbury, G.W., Fuller, H.K. \& WilletT, E.L. (1941) Preservation of bovine spermatozoa in yolk-citrate diluent and field results from its use. $J$. Dairy $S c i$. 23, 905-910.

ScoTr, T.W. \& DAwson, R.M.C. (1968) Metabolism of phospholipids by spermatozoa and seminal plasma. Biochem. J. 108, 457-463.

Suominen, J. \& Setchell, B.P. (1972) Enzymes and trypsin inhibitor in the rete testis fluids of rams and boars. J. Reprod. Fert. 30, 235-245.

Voglmayr, J.K., ScotT, T.W., Setchell, B.P. \& WAITES, G.M.H. (1967) Metabolism of testicular spermatozoa and characteristics of testicular fluid collected from conscious rams. J. Reprod. Fert. 14, 87-99.

WATSON, P.F. (1975) The interaction of egg yolk and ram spermatozoa studied with a fluorescent probe. $J$. Reprod. Fert. 42, 105-111.

Watson, P.F. \& MAR rIN, I.C.A. (1974) Regions of the freezing curve causing changes in structure and viability of ram spermatozoa. Nature, Lond. 251, 315-316.

Received 8 December 1977 